\title{
EXAMEN DETALLADO DE LA EXCLUSIÓN DEL DERECHO SOCIETARIO EN EL REGLAMENTO ROMA I AL HILO DEL ASUNTO VEREIN FÜR KONSUMENTENINFORMATION: FORTALEZA LEGAL HACIA EL CONSUMIDOR INVERSOR
}

\author{
DETAILED EXAM OF THE EXCLUSION OF COMPANY LAW IN \\ THE ROME I REGULATION TO THE THREAD OF THE VEREIN \\ FÜR KONSUMENTENINFORMATION CASE: LEGAL STRENGTH \\ TOWARDS THE INVESTOR CONSUMER
}

\author{
David Carrizo Aguado \\ Profesor Ayudante Doctor de Derecho internacional privado \\ Universidad de León \\ orcid ID: 0000-0002-9427-287X
}

Recibido: 09.03.2020 / Aceptado: 27.03.2020

DOI: https://doi.org/10.20318/cdt.2020.5642

\begin{abstract}
Resumen: La tutela a los consumidores en el ámbito del Reglamento (CE) 593/2008 se sustenta en dos pilares: por un lado, las condiciones y límites de la autonomía de la voluntad en la elección de ley aplicable y, por otro, la determinación de cuándo una prestación de servicios se realiza exclusivamente en un Estado distinto del de la residencia habitual del consumidor a los efectos de excluir dicho contrato de la protección otorgada por el artículo 6 de la mencionada norma. El estudio gira en torno a ofrecer un razonamiento del quid de la exclusión del ámbito de aplicación material del Reglamento (CE) 593/2008 en relación a un contrato fiduciario cuyo objeto es la administración de una participación en una sociedad comanditaria. Las operaciones como la venta o la fiducia referidas a participaciones sociales pueden plantear cuestiones pertenecientes al Derecho de sociedades, pero no ocurre lo mismo con los contratos subyacentes a dichas operaciones. En particular, la mera circunstancia de que un contrato tenga un vínculo con «cuestiones pertenecientes al Derecho de sociedades» no tiene por efecto eliminar del perímetro material del Reglamento (CE) 593/2008 aquellas obligaciones que tienen su origen en dicho contrato.

Palabras clave: Derecho de sociedades internacional, Ley aplicable, cláusulas abusivas, contratación a distancia, operaciones de consumo transfronterizas.
\end{abstract}

Abstract: The guardianship of consumers within the scope of Regulation (EC) 593/2008 is based on two pillars: on the one hand, the conditions and limits of the autonomy of the will in the choice of applicable law and, on the other, the determination of when a provision of services is carried out exclusively in a State other than that of the habitual residence of the consumer for the purpose of excluding said contract from the protection granted by article 6 of the said norm. The study revolves around offering a reasoning for the exclusion of the scope of material application of Regulation (EC) 593/2008 in relation to a fiduciary contract whose purpose is the administration of a participation in a limited partnership. Operations such as

*Este trabajo se ha realizado en el marco del proyecto de investigación emergente $\mathrm{I}+\mathrm{D}+\mathrm{i}$ financiado por la Generalitat Valenciana (con referencia GV/2019/118) titulado "La tutela de los derechos en el entorno digital: nuevos retos, desafíos y oportunidades", Investigador Principal José Juan Castelló Pastor del que el autor es miembro del grupo de investigación. 
sale or trust related to social interests may raise issues pertaining to company law, but the same does not occur with the contracts underlying those operations. In particular, the mere circumstance that a contract has a link with "matters pertaining to company law" does not have the effect of removing from the material perimeter of Regulation (EC) 593/2008 those obligations that have their origin in that contract.

Keywords: International company law, applicable law, abusive clauses, distance contracting, cross-border consumer contract.

Sumario: I. Relato de los hechos que dieron lugar al litigio. 1.1. Planteamiento inicial. 1.2. $\mathrm{La}$ «tela de araña» en relación a la situación fáctica. II. Análisis del ámbito de aplicación material del Reglamento (CE) 593/2008: exclusión del Derecho societario. 1. Apunte inicial. 2. Posicionamiento jurisprudencial. III. Régimen jurídico del contrato de prestación de servicios transfronterizos: Hilo conductor para su clasificación como contrato de consumo. 1. Caracteres esenciales emanados de la praxis jurisprudencial y doctrinal. 2. Contratación a distancia: especial referencia al artículo 6 Reglamento (CE) 593/2008. 3. Requisitos de activación del sistema protector del Derecho de consumo internacional para la concreción de la Ley aplicable. A) Exclusiva protección al consumidor pasivo. B) La «actividad dirigida» en el Reglamento (CE) 593/2008. C) Diferenciación entre consumidor activo y consumidor pasivo. D) Contratos concluidos vía on line. IV. Las cláusulas abusivas a debate en torno a la Directiva 93/13/CEE. A. Aclaración preliminar. B. Reglas de juego entre la Directiva 93/13/CEE y el Reglamento (CE) 593/2008. C. ¿Quién es un verdadero consumidor? D. Diagnóstico de las cláusulas no negociadas en la práctica comercial internacional.

\section{Relato de los hechos que dieron lugar al litigio}

\section{Planteamiento inicial}

1. La base sobre la que se sustenta la STJUE de 3 de octubre de 2019, asunto C-272/18, Verein für Konsumenteninformation ${ }^{1}$, tiene como fin ofrecer una clara interpretación de los artículos 1, apartado 2, letra e), y 5, apartado 4, letra b), del Convenio sobre la ley aplicable a las obligaciones contractuales, abierto a la firma en Roma el 19 de junio de 1980, «Convenio de Roma» ${ }^{2}$, de los artículos 1, apartado 2, letra f), y 6, apartado 4, letra b), del Reglamento (CE) $n .^{\circ}$ 593/2008 del Parlamento Europeo y del Consejo, de 17 de junio de 2008, sobre la ley aplicable a las obligaciones contractuales, Roma $\mathrm{I}^{3}$, y del artículo 3, apartado 1, de la Directiva 93/13/CEE del Consejo, de 5 de abril de 1993, sobre las cláusulas abusivas en los contratos celebrados con consumidores ${ }^{4}$.

\section{La «tela de araña» en relación a la situación fáctica}

2. La cuestión prejudicial se ha presentado en el contexto de un litigio entre la Verein für Konsumenteninformation, asociación austriaca para la información de los consumidores conocida por el acrónimo «VKI», y la sociedad alemana Treuhand- und Verwaltungsgesellschaft für Publikumsfonds $\mathrm{mbH} \& \mathrm{Co} \mathrm{KG}$, bajo las sigas «TVP», en relación con la licitud de una cláusula de elección de la ley aplicable que esta última incorpora en contratos celebrados con inversores privados.

3. «VKI», establecida en Austria, en calidad de asociación de consumidores sin ánimo de lucro, interpone una acción de cesación con el fin de proteger los intereses de los consumidores que residen en Austria.

\footnotetext{
${ }^{1}$ EU:C:2019:827.

${ }^{2}$ DOCE núm. 266, de 9 de octubre de 1980.

${ }^{3}$ DOUE núm. 177, de 4 de julio de 2008.

${ }^{4}$ DOCE núm. 95, de 21 de abril de 1993.
} 
«TVP», con domicilio social en Hamburgo, filial al $100 \%$ del grupo Münchmeyer Capital AG Hamburg, «Grupo MPC», crea y comercializa fondos de inversión de tipo cerrado. Dichos fondos se constituyen en forma de sociedades comanditarias sujetas al Derecho alemán, en las que pueden participar inversores privados e institucionales como socios comanditarios.

4. Hasta finales del año 2014, existía un contrato de dominio y cesión de beneficios entre «TVP» y su sociedad matriz de manera que, la dirección de «TVP» estaba subordinada al grupo MPC. Entre las numerosas sociedades comanditarias creadas por el grupo MPC figura el «Fondo 43». «TPV», en calidad de fiduciaria y socia comanditaria fundacional, participa con dicho fondo. Si bien, «Fondo 43» no fue comercializado solamente en Austria, pues se abrió una cuenta fiduciaria en un banco austriaco, en la que habían de efectuarse los pagos relativos a las participaciones de los inversores residentes en Austria.

5. En el mecanismo dispuesto por los estatutos sociales del «Fondo 43», «TVP» está facultada para incorporar a nuevos socios comanditarios. Los inversores interesados, futuros socios comanditarios, ingresan una participación en la cuenta fiduciaria de este fondo y de este modo, los inversores entran en el fondo indirectamente como fiduciantes por medio de «TVP».

De este modo, «TVP» no se encarga ella misma de buscar nuevos inversores, sino que esta actividad la realiza CPM, filial al $100 \%$ del grupo MPC. Las ofertas y anuncios selectivos son transmitidos a consumidores austriacos por esta filial y, también, por otros intermediarios, como bancos austriacos o asesores financieros. «TVP», que no posee ningún establecimiento ni sucursal en Austria, no tiene contacto directo con los socios comanditarios ni presta por sí misma ningún servicio de asesoramiento.

6. Por consiguiente, los inversores pueden participar en los fondos dirigiendo a «TVP» una declaración de adhesión en forma de oferta de celebración de un contrato fiduciario. De esta suerte, TVP ofrece a los inversores la prestación de un servicio fiduciario y, en todo caso, asume la participación comanditaria por cuenta del inversor y la administra a título fiduciario. Si bien, ejerce los derechos inherentes a la participación en nombre propio, pero por cuenta del inversor, y le remite a este los dividendos, así como todas los demás ventajas patrimoniales derivadas de su participación. «TVP» redirige permanentemente a los inversores la información que recibe del fondo sobre el curso de la actividad de la sociedad en la que estos poseen una participación.

7. El modo de actuar de «TPV» en el tráfico jurídico es a través de modelos de contrato en sus operaciones comerciales con los inversores privados. De esta forma, el conjunto de inversores radicados en Austria firman la declaración de adhesión y los colaboradores de «TVP» lo aceptan en ese mismo país. Experimenta gran relevancia la cláusula no negociada tanto de Competencia judicial internacional, así como de Ley aplicable impuesta en el contrato: "El presente contrato fiduciario se rige por el Derecho de la República Federal de Alemania. El lugar de cumplimiento y el fuero judicial para todo litigio derivado del presente contrato y en relación con su celebración es el correspondiente al domicilio social de la fiduciaria (Alemania), siempre que este pacto esté permitido por la ley".

8. En este escenario, interesa destacar la actuación práctica que manifiesta «TVP», pues dirige sus prestaciones de servicios al mercado austriaco y gestiona un sitio web, www.tvp-treuhand.at, desde el que se remite al usuario al sitio web alemán www.tvp-treuhand.de. En consecuencia, los inversores austriacos pueden registrarse a través de esta webpage y todos aquellos inversores que lo manifiesten expresamente pueden votar en línea junto con la consulta de los documentos que se les han remitido por vía electrónica. 


\section{Análisis del ámbito de aplicación material del Reglamento (CE) 593/2008: aislamiento del De- recho societario}

\section{Apunte inicial}

9. El Reglamento (CE) 593/2008 se aplica para determinar el Derecho aplicable a las obligaciones contractuales en aquellas situaciones en las que exista un conflicto de leyes en materia civil y mercantil ${ }^{5}$.

El Tribunal de Luxemburgo ha declarado que surge una obligación contractual en la que subsista un compromiso libremente asumido por una parte frente a otra ${ }^{6}$.

\section{Posicionamiento jurisprudencial}

10. Con carácter previo, es preciso señalar que la eliminación del ámbito de aplicación material del Reglamento (CE) 593/2008 de aquellas cuestiones pertenecientes al Derecho de sociedades, asociaciones y otras personas jurídicas, relativas a cuestiones como la constitución, mediante registro o de otro modo, la capacidad jurídica, el funcionamiento interno y la disolución de sociedades, asociaciones y otras personas jurídicas, queda establecida por el legislador europeo en su artículo 1, apartado 2, letra f) 7 .

Este planteamiento queda confirmado por el Informe relativo al Convenio sobre la Ley Aplicable a las Obligaciones Contractuales, elaborado por los profesores Mario Giuliano y Paul Lagarde, según el cual la exclusión de dichas cuestiones del ámbito de aplicación del Convenio sobre la Ley Aplicable a las Obligaciones Contractuales abierto a la firma en Roma el 19 de junio de 1980, que fue remplazado entre los Estados miembros, por el Reglamento (CE) 593/2008, contempla todos los actos de naturaleza compleja necesarios para la constitución de una sociedad o que rigen su vida interna o su disolución, esto es, actos pertenecientes a la esfera del Derecho de sociedades.

11. En más de una ocasión, el Alto Tribunal Europeo ha apreciado que, la Ley aplicable a ciertas obligaciones complejas, como puede ser el contrato de empréstito celebrado por una sociedad con anterioridad a su absorción transfronteriza, el cual estaba comprendido en el ámbito de aplicación del Convenio de Roma, seguía siendo la que era aplicable al contrato antes de la fusión ${ }^{8}$.

12. Conviene tener presente el prolijo análisis realizado por el Abogado General, Henrik Saugmandsgaard, en sus conclusiones en torno al asunto Verein für Konsumenteninformation, en las que afir-

${ }^{5}$ El Reglamento (CE) 593/2008 sólo se aplica a las obligaciones contractuales que nacen de contratos sometidos al Derecho Privado, es decir, los contratos que celebran entre sí y que vinculan exclusivamente a particulares y entes privados (Cfr. A-L. Calvo Caravaca / J. Carrascosa González, Derecho Internacional Privado, vol. II, 18 a ed., Comares, Granada, 2018, p. 947).

${ }^{6}$ STJUE de 17 de septiembre de 2002, asunto C-334/00, Tacconi (EU:C:2002:499); STJUE de 20 de enero de 2005, asunto C-27/02, Engler (EU:C:2005:33); STJUE de 14 de marzo de 2013, asunto C-419/11, Česká spořitelna (EU:C:2013:165).

7 Así lo corrobora el TJUE en su reciente sentencia de 8 de mayo de 2019, asunto C25/18, Brian Andrew Kerr (EU:C:2019:376). Como acertadamente señala De Miguel Asensio, es interesante destacar que el TJUE se aleja del planteamiento del Abogado General, quien había entendido que una reclamación de pago se halla excluida del ámbito de aplicación material del Reglamento Roma (CE) 593/2008. El Tribunal pone de relieve que esa exclusión se limita a los aspectos orgánicos de las sociedades u otras personas jurídicas, sin abarcar la reclamación de cuotas anuales que se enmarcan "en la esfera del Derecho general en materia de obligaciones contractuales" y, por lo tanto, quedan comprendidas en el ámbito de aplicación del Reglamento Roma I (Vid. P.A. De Miguel Asensio, «Propiedad horizontal y Derecho internacional privado», http://pedrodemiguelasensio.blogspot.com/2019/05/propiedad-horizontal-y-derecho.html). Esta misma postura es mantenida por Ma.P. DiAgo DIAGO, «Reclamación del pago de las cuotas de la comunidad cuando los propietarios de la vivienda están domiciliados en el extranjero: sentencia del Tribunal de Justicia de la Unión Europea de 8 de mayo de 2019. Asunto C-25/18: Kerr, La Ley Unión Europea, núm. 74, 2019, versión on line.

8 STJUE de 7 de abril de 2016, asunto C 483/14, KA Finanz (EU:C:2016:205). En torno a la misma, vid. I. LAURENCE, "Fusions transfrontalières et protection des créanciers", Europe, núm. 6, 2016, pp. 40-41; S. EMANUELE, "La fusione per incorporazione transfrontaliera tra continuità dei rapporti giuridici e tutela dei creditori. Il caso KA Finanz AG", Rivista di diritto societario, núm. 1, 2017, pp. 150-156; T. THIERRY, "L'arrêt KA Finanz AG: la fusion transfrontalière et la protection des créanciers", Revue de droit commercial belge, 2018, pp. 64-70. 
ma que, las operaciones como la venta o la fiducia referidas a participaciones sociales pueden plantear cuestiones pertenecientes al Derecho de sociedades, pero no ocurre lo mismo con los contratos subyacentes a dichas operaciones. En particular, la mera circunstancia de que un contrato tenga un vínculo con «cuestiones pertenecientes al Derecho de sociedades» no tiene por efecto excluir del ámbito de aplicación del Reglamento (CE) 593/2008, las obligaciones que tienen su origen en dicho contrato. Por lo tanto, estas cuestiones no deben confundirse con las cuestiones de carácter contractual ${ }^{9}$.

\section{Régimen jurídico del contrato de prestación de servicios transfronterizos: Hilo conductor para su clasificación como contrato de consumo}

\section{Caracteres esenciales emanados de la praxis jurisprudencial y doctrinal}

13. En lo que respecta al análisis de la categoría “contrato de prestación de servicios", el TJUE ha realizado ciertos apuntes significativos, habida cuenta de que la interpretación de ese concepto enmarcado en el artículo 6, apartado 1, letra a) Reglamento (CE) 593/2008 debe hacerse en paralelo con su significado en los artículos 7, apartado1 Reglamento (UE) 1215/2012 ${ }^{10}$ y 4, apartado 1, letra b) Reglamento (CE) 593/2008.

14. La base que sustenta esta fórmula contractual, en el asunto objeto de este comentario, resulta del compromiso de llevar a cabo una determinada actividad a cambio de una remuneración. De modo particular, el juzgador europeo concluye que un contrato fiduciario en el que la fiduciaria ejerce una actividad consistente en la administración del bien objeto del contrato fiduciario a cambio de una remuneración, es un contrato de prestación de servicios ${ }^{11}$.

15. Como acertadamente apunta la doctrina, el concepto de prestación de servicios debe interpretarse en sentido muy amplio, pues dicho contrato comprende tanto obligaciones de medio como de resultado, así como obligaciones de hacer y de no hacer, e incluso comporta la obligación de poner a disposición una cosa, como es el caso del préstamo ${ }^{12}$.

16. Tal y como se enunció al comienzo de este epígrafe, es necesario acudir a criterios utilizados por el Tribunal de Luxemburgo que son aclaratorios en el marco de la tarea espinosa de establecer la determinación del lugar de la prestación de servicios, esencialmente en supuestos efectuados a distancia. Así, cuando exista la situación de una pluralidad de lugares de prestación, se deberá atender en el que deba efectuarse la principal prestación de servicios, en función de criterios económicos, siendo determinante los servicios cuya prestación esté vinculada al contenido propio del contrato y no a las actividades preparatorias con vistas a la prestación del servicio. En cualquier caso, se deben respetar los objetivos de previsibilidad y de proximidad $^{13}$.

\footnotetext{
${ }^{9}$ De hecho, la acción de cesación entablada por la «VKI» versa sobre el carácter abusivo y, por ende, la licitud de determinadas cláusulas de los contratos fiduciarios en cuestión. Por consiguiente, las cuestiones que plantea el litigio principal pertenecen al ámbito de aplicación de la lex contractus y, por ende, del Reglamento (CE) 593/2008.

${ }^{10}$ DOUE núm. 351, de 20 de diciembre de 2012.

${ }^{11}$ Vid. apartados 46 y 47 del asunto C-272/18, Verein für Konsumenteninformation.

${ }^{12}$ En cuanto a los contratos complejos, si la finalidad económica del contrato es la prestación del servicio y no la transmisión de la propiedad, este debe calificarse como contrato de prestación de servicios. Por el contrario, si el fin del contrato es la transmisión de la propiedad de una cosa en sí, el contrato no será una prestación de servicios. Vid. en este sentido, A-L. Calvo Caravaca y J. Carrascosa González, Litigación internacional en la Unión Europea I. Competencia judicial y validez de resoluciones en materia civil y mercantil en la Unión Europea. Comentario al Reglamento Bruselas I Bis, Thomson Reuters Aranzadi, Navarra, 2017, pp. 161-164.

13 STJUE de 9 de julio de 2009, asunto C-204/08, Rehder (EU:C:2009:439); STJUE de 11 de marzo de 2010, asunto C-19/09, Wood Floor Solutions Andreas Domberger (EU:C:2010:137).
} 
17. No dejando de lado lo dificultoso que conlleva la prestación de servicios a distancia, como ocurre en los supuestos de aquellos servicios en línea, se puede afirmar que, las obligaciones de la parte contratante que ofrece servicios a través de Internet son normalmente obligaciones de puesta a disposición o, a lo sumo, de remisión, pues quien presta los servicios se limita típicamente bien a hacer posible que el cliente pueda acceder al sistema en el que se almacena la información requerida y consultarla $\mathrm{o}$, incluso, obtener una copias mediante la transmisión a la memoria de su ordenador. La configuración de estos supuestos parece conducir a localizar el lugar de ejecución de estas obligaciones donde se pone a disposición o se emite la información, es decir, donde se encuentran físicamente en la Red los recursos utilizados ${ }^{14}$. En definitiva, el empleo del establecimiento de la parte que presta los servicios como elemento decisorio para fijar el lugar de ejecución resulta aconsejable por ser previsible y expresión de un vínculo significativo de proximidad, y, sin lugar a dudas, favorece la correlación forum-ius ${ }^{15}$.

\section{Contratación a distancia: especial referencia al artículo 6 Reglamento (CE) 593/2008}

18. De un mayor calado reviste el estudio del artículo 6 Reglamento (CE) 593/2008, específicamente en lo que concierne a la prestación de servicios fuera del Estado donde el consumidor posee su residencia habitual.

19. El asunto Verein Für Konsumenteninformation es trascendental en la medida en que, contribuye a esfumarse eventuales dudas que pudieran existir acerca de cuál debe ser el tratamiento de los contratos en los que dichos servicios se prestan a distancia, e incluso, el prestador del servicio lleva a cabo su actividad en un país distinto al de la residencia habitual del consumidor, pero sin que este se desplace de su residencia habitual. De ahí, la repercusión de la sentencia, ya que, con sensatez, el Tribunal de Justicia opta por una interpretación restrictiva de la exclusión, de modo que, los contratos de prestación transfronteriza de servicios a distancia en los que el consumidor permanece en el país de su residencia habitual no se verán afectados por la exclusión establecida por el artículo 6, apartado 4, letra a).

Vale decir, cuando el lugar de realización material de la prestación se encuentra en un país distinto de aquel en el que el consumidor la recibe, debe considerarse que los servicios solo se prestan «exclusivamente» fuera del Estado miembro de residencia habitual del consumidor cuando este no tiene ninguna posibilidad de recibir dichos servicios en su Estado de residencia y tiene que desplazarse al extranjero para ello ${ }^{16}$.

\section{Requisitos de activación del sistema protector del Derecho de consumo internacional para la concreción de la Ley aplicable}

20. Conviene poner de manifiesto que, para otorgar una tutela efectiva $y$, por ende, aplicar el régimen de protección -favor consommatoris- resulta necesario que concurran ciertos requisitos.

\footnotetext{
${ }^{14}$ Ahora bien, la ubicación de esos recursos informáticos puede resultar aleatoria y por completo desconocida e imprevisible para la otra parte, siendo muy sencillo su desplazamiento de un país a otro por medio del cambio de servidor empleado, lo que limite la posibilidad de una determinación fáctica del lugar de ejecución en esas circunstancias (Vid. P.A. DE Miguel AsENsio, "Contratación comercial internacional" en J.C. Fernández Rozas, R. Arenas García y P.A. De Miguel Asensio, Derecho de los negocios internacionales, $5^{\mathrm{a}}$ ed., Iustel, Madrid, 2016, p. 331).

${ }^{15}$ P.A. De Miguel Asensio, "El lugar de ejecución de los contratos de prestación de servicios como criterio atributivo de competencia”, en J.J. Forner i Delaygua, C. González Beilfuss y R. Viñas Farré (coords.) Entre Bruselas y La Haya: Estudios sobre la unificación internacional y regional del Derecho internacional privado. Liber amicorum Alegría Borrás, Marcial Pons, Madrid, 2013, p. 306.

${ }^{16} \mathrm{Vid}$. apartado 52 del asunto C-272/18, Verein für Konsumenteninformation. Vid. un notable comentario, F. RIELÄNDER, "Choice-of-law clauses in pre-formulated fiduciary contracts for holding shares: Consolidation of the test of unfairness regarding choice-of-law clauses under Art. 3(1) Directive 93/13/EEC", IPRax: Praxis des Internationalen Privat- und Verfahrensrechts, Vol. 10, núm. 3, 2020.
} 
Con todo, para que el mercado único beneficie de manera efectiva a los consumidores debe asegurar no sólo la adquisición de bienes y servicios sino la obtención de reparación o indemnización en caso de litigio; por ello, su verdadera protección conllevará el aumento de confianza en el mercado europeo y máxime en la era del boom digital en la que estamos inmersos ${ }^{17}$. El futuro camina digitalmente hacia un consumo masivo online y en dicho paisaje social virtual es necesario que el TJUE abra vías de protección al consumidor de un modo evolutivo ${ }^{18}$.

\section{A) Exclusiva protección al consumidor pasivo}

21. Como punto de partida, el artículo 6 Reglamento (CE) 593/2008 ${ }^{19}$, especifica de manera bastante clarividente quién debe considerarse consumidor ${ }^{20}$ y quién profesional $\mathrm{y}$, así, poder enmarcar la relación que pudiere surgir entre ambos, bajo la modalidad contractual «contratos de consumo» ${ }^{21}$.

El principal objetivo que persigue el citado precepto es proteger la posición jurídica del consumidor $^{22}$, pues en ningún caso, poseen el mismo poder de negociación ${ }^{23}$. La consecuencia inmediata es que la elección de la ley aplicable no sea impuesta por el empresario, dada la posición jurídica de inferioridad en la que se encuentra el consumidor ${ }^{24}$.

${ }^{17}$ D. CARrizo Aguado, “«Trampantojo» de foros ante los profusos incumplimientos llevados a cabo por la compañía Ryanair en vuelos internacionales", Cuadernos de derecho transnacional, vol. 11, núm. 2, 2019, p. 507.

${ }^{18}$ Como muy bien afirma un sólido sector doctrinal, es preciso que, en futuras reformas del Reglamento (UE) 1215/2012 se incorporen los conceptos que el TJUE ha creado en relación con la competencia judicial en el sector del consumo transfronterizo: los conceptos de "acto de consumo", "consumidor", "profesional", y "actividad dirigida", por ejemplo, deberían dejar de ser conceptos jurisprudenciales para pasar a ser conceptos legales ( $C f r$. A-L. Calvo CaravacA, "Consumer contracts in the European Court of Justice case law. Latest trends", Cuadernos de Derecho Transnacional, vol. 12, núm. 1, 2020, pp. 86-96). Este planteamiento es, sin lugar a dudas, trasladable a Ley aplicable regulado por el Reglamento (CE) 593/2008.

${ }^{19}$ La mejora en la protección de los consumidores dispensada por el artículo 6 Reglamento (CE) 593/2008, se refleja en la enorme importancia que supone la protección del consumidor en el marco de la UE (Vid. VOLKER, B.: "Rome I Regulation a -Mostly-Unified Private International Law of Contractual Relationships within-Most-of the European Union", Journal of Law and Commerce, vol. 29, 2011, pp. 248-250).

${ }^{20}$ El artículo 6 Reglamento (CE) 593/2008, define al consumidor como aquella persona física que entra en contacto con un profesional con el propósito de poder ser considerado en contraposición a éste último, fuera de la esfera de actuación del empresario (Vid. F.J. Garcimartín Alferez, "The Rome I Regulation: Exceptions to the Rule on Consumer Contracts and Financial Instruments", Journal of Private International Law, vol. 5, Issue 1, 2009, pp. 85-103; M. McParland, The Rome I Regulation on the Law Applicable to Contractual Obligations, Oxford University Press, United Kingdom, 2015, pp. 524-525; F. Rango, "The Law Applicable to Consumer Contracts under the Rome I Regulation" en F. Ferrari, / S. Leible, (EDS.), Rome I Regulation. The Law Applicable to Contractual Obligations in Europe, Sellier, Munich, 2009, pp. 133-137; B. UBERTAZZI, Il Regolamento Roma I sulla legge applicabile alle obbligazioni contrattuali, Guiffré editore, Milán, 2008, pp. 82-88).

${ }^{21}$ Interesa recordar que, las personas jurídicas no tienen la consideración de consumidores para el Reglamento (CE) $593 / 2008$, por lo que los contratos celebrados por sociedades en calidad de consumidores no quedan sujetos al régimen que para ellos consagra el Reglamento (Vid. P. JuÁrez Pérez, "La ley rectora de los contratos internacionales de consumo: el sistema del Reglamento n ${ }^{\circ}$ 593/2008 ("Roma I")", Estudios de Deusto: revista de la Universidad de Deusto, vol. 58, núm. 1, 2010, p. 53).

${ }^{22}$ Nadie cuestiona hoy la necesidad de que las normas jurídicas asuman la misión de acudir al amparo de un consumidor que, para satisfacer sus necesidades, se encuentra inmerso en ofertas comerciales de difícil diferenciación, en mensajes subliminales que le someten a poderosos instrumentos de consumo y en técnicas de mercado agresivas que utilizan, casi sin límites, a publicidad. Es necesaria por tanto, la construcción de un derecho tuitivo, integrante de un orden público económico, que genere un marco estable en el que el consumidor se sienta protegido en sus relaciones con los profesionales productores de bienes y servicios. A esta necesidad han sido sensibles las organizaciones económicas y políticas, tanto nacionales como supranacionales (Vid. F.E. Puerta Seguido / R. Serrano Lozano, Fundamentos jurídicos para el desarrollo de un sistema público de protección al consumidor, Centro de Estudios de Consumo, Toledo, 2006, pp. 5-8).

${ }^{23}$ El legislador europeo establece reglas especiales de competencia judicial internacional y Ley aplicable para los litigios derivados de las relaciones contractuales con consumidores. Este tipo de contratos se caracteriza por la existencia de una posición de asimetría entre las partes intervinientes (profesional-consumidor) que encuentra su reflejo en la dimensión procesal: D. CARRIzo Aguado, "La relación de causalidad como indicio justificativo de la "actividad dirigida» en el contrato internacional de consumo: análisis del foro de protección de la parte débil”, Cuadernos de derecho transnacional, vol. 8, núm. 1, 2016, pp. 301-317.

${ }^{24}$ En el marco de la categoría contractual de consumo, el principio tuitivo ha justificado una amplia limitación al ejercicio de la autonomía conflictual. Por consiguiente, de manera análoga en el ámbito de los contratos de franquicia y de distribución, el principio tuitivo se ha expresado en términos, más que de justicia material, de justicia conflictual. (Vid. H. AgUILAR GriedER, "Los contratos internacionales de distribución comercial en el Reglamento Roma I", Cuadernos de derecho transnacional, vol. 
22. En el asunto objeto de este estudio, resalta el límite impuesto por el TJUE en el sentido de que las partes, en un contrato de consumo al que se adhieren, no pueden pactar el lugar exclusivo de prestación del servicio si ello supone alterar la protección que pretende el artículo 6 Reglamento (CE) 593/2008. A este respecto, la excepción de su artículo 6, apartado 4, solamente procederá en los supuestos en que la parte consumidora del contrato no tenga ninguna posibilidad de recibir los servicios contratados en el país de su residencia habitual y deba desplazarse al extranjero para ello ${ }^{25}$.

23. Habida cuenta del reciente asunto Jana Petruchová, de 3 de octubre de $2019^{26}$, el juzgador europeo efectúa una notable analogía entre los Reglamentos (CE) 593/2008 y (UE) 1215/2012 en materia de obligaciones contractuales de consumo. De esta manera, clarifica que, aunque el concepto de «consumidor» se define en el artículo 6, apartado 1, Reglamento (CE) 593/2008 en prácticamente los mismos términos que los empleados en el artículo 17, apartado 1, del Reglamento (UE) 1215/2012, el artículo 6, apartado 4, letra d) Reglamento (CE) 593/2008, leído a la luz de sus considerandos 28 y 30 , excluye de las normas aplicables a los contratos de consumo fijadas en el artículo 6, apartados 1 y 2, de ese Reglamento, a los «derechos y obligaciones que constituyan un instrumento financiero».

Pues bien, como resulta del considerando 30 de dicho Reglamento, a efectos del Reglamento (CE) 593/2008 se entiende por instrumentos financieros aquellos mencionados en el artículo 4 de la Directiva 2004/3927. Con todo, advierte que, el Reglamento (CE) 593/2008 y el Reglamento (UE) 1215/2012 persiguen objetivos distintos. Así, el Reglamento (CE) 593/2008 se aplica a las obligaciones contractuales en materia civil y mercantil en las situaciones que impliquen un conflicto de leyes, con el fin de determinar el Derecho material aplicable ${ }^{28}$, mientras que el Reglamento (UE) 1215/2012 tiene por objeto fijar las normas que permitan determinar el tribunal competente para resolver un litigio en materia civil y mercantil que verse, en particular, sobre un contrato celebrado entre un profesional y una persona que actúa con un fin ajeno a su actividad profesional, de manera que esta última quede protegida en tal situación ${ }^{29}$.

1, núm. 1, 2009, pp. 33-35). La distribución comercial es la forma más común de hacer llegar los productos del fabricante al consumidor; éstos en gran medida son de carácter internacional, puesto que la globalización está impulsando a las empresas a buscar mercados en el exterior (Vid. J. Rodríguez Rodrigo, Contratos internacionales de distribución comercial en el Derecho internacional de la Unión Europea, Comares, Granada, 2013).

${ }^{25}$ La doctrina estima que, las condiciones restrictivas van en la línea del propio TJUE de limitar y restringir las excepciones a los principios generales y objetivos perseguidos para garantizar el cumplimiento de lo esperado por el legislador, es decir, la protección del consumidor como parte débil en la relación contractual: J. M. De Dios MARCER, "Autonomía de la voluntad, protección del consumidor y Derecho aplicable a los contratos de consumo en el Reglamento 593/2008. Sentencia del Tribunal de Justicia de 3 de octubre de 2019, Asunto C-272/18: Verein für Konsumenteninformation y TVP Treuhand-und Verwaltungsgesellschaft für Publikumsfonds mbH \& Co KG”, La Ley Unión Europea, núm. 78, 2020, versión on line.

${ }^{26}$ STJUE de 3 de octubre de 2019, asunto C-208/18, Jana Petruchová, EU:C:2019:825. Cierto sector doctrinal intuye en dicho pronunciamiento una excesiva compartimentación en la interpretación de distintas normas puede conllevar una cierta dosis de inseguridad jurídica: G. Romero García-Mora, "La condición de consumidor en los casos de actividad inversora", Diario La Ley, núm. 9528, 2019, versión on line. Hay que tener presente que, la inquietud jurídica a la que se enfrentan los clientes minoristas, esencialmente, por la imposición de cláusulas predispuestas a cargo de las compañías financieras, ha sido uno de los principales detonantes en la litigiosidad internacional; en el asunto Petruchová se ha observado, por un lado, la inviabilidad jurídica de sumisión a favor de los tribunales de la compañía inversora, y, de otro, la formidable calificación de consumidor a favor del inversionista, $\mathrm{y}$, por ende, beneficiario del régimen procesal conformado por los foros de los contratos de consumo instaurados por el Reglamento (UE) 1215/2012: Vid. in extenso, D. CARRIzo Aguado, "Nuevas coordenadas en las transacciones financieras internacionales: la teoría «Petruchová»”, Revista de Derecho del Sistema Financiero, núm. 0, 2020, en prensa.

${ }^{27}$ Directiva 2004/39/CE del Parlamento Europeo y del Consejo, de 21 de abril de 2004, relativa a los mercados de instrumentos financieros, por la que se modifican las Directivas 85/611/CEE y 93/6/CEE del Consejo y la Directiva 2000/12/CE del Parlamento Europeo y del Consejo y se deroga la Directiva 93/22/CEE del Consejo (DO núm. L 145, de 30 de abril de 2004).

${ }^{28}$ No se ha de perder de vista que el propósito del Reglamento (CE) 593/2008 es la unificación de las normas de conflicto de los Estados miembros de la Unión referidas a los contratos, desactivando toda posibilidad de forum shopping, y, así, con independencia de cuál sea la jurisdicción del Estado miembro ante el que pueda plantearse el litigio, que la ley aplicable sea siempre la misma (Vid. J.I. PARedes Pérez, "La noción de consumidor a efectos de la aplicación de los foros de protección del Reglamento de Bruselas I bis a litigios relativos a instrumentos financieros y de inversión. Sentencia del Tribunal de Justicia de 3 de octubre de 2019, asunto C-208/18: Petruchová”, La Ley Unión Europea, núm. 75, 2019, versión on line.

${ }^{29}$ Especial atención revisten los apartados 62 y 64 del asunto Jana Petruchová. 
24. De lo señalado hasta el momento se deduce que, no se tutela al consumidor activo ${ }^{30}$, el cual celebra un contrato de consumo desplazándose a otro mercado o tomando la iniciativa negocial; se protege exclusivamente al consumidor pasivo, que es quien se ve asaltado en su país por ofertas de consumo de empresarios y profesionales. Son estos quienes desean celebrar un contrato con los consumidores en o hacia otro país; es más, el consumidor puede incluso no saber que el empresario oferente tiene su sede en un país extranjero ${ }^{31}$.

\section{B) La «actividad dirigida» en el Reglamento (CE) 593/2008}

25. Para que se proceda a la aplicación del régimen específico del artículo 6 Reglamento (CE) $593 / 2008$, y en consecuencia la ley de la residencia habitual del consumidor, basta con que el profesional ejerza sus actividades comerciales o profesionales en el país donde el consumidor tenga su residencia habitual, o simplemente por cualquier medio dirija estas actividades a ese país, o a distintos países, pero incluido también el de la residencia habitual del consumidor. En caso contrario, el contrato celebrado por el consumidor seguirá las reglas generales de ley aplicable contenidas en los artículos 3 y 4 Reglamento (CE) 593/2008. Por esta razón, la mayor dificultad radica en determinar si el profesional ha dirigido o no sus actividades comerciales hacia el país de la residencia habitual del consumidor ${ }^{32}$.

26. La expresión enmarcada en este epígrafe ha exigido complemento jurisprudencial emanado del Alto Tribunal Europeo para su puesta en marcha en la práctica. Así, en sendos pronunciamientos ${ }^{33}$, el TJUE ha establecido una serie de indicios que permiten determinar en qué casos puede entenderse que una actividad está «dirigida» al Estado miembro del domicilio del consumidor.

Entre estos parámetros podemos destacar los seis siguientes: a) aquellas manifestaciones expresas para atraer clientes de un determinado Estado miembro; b) los gastos de remisión a páginas web en Internet que han sido prestados por una empresa que explota un motor de búsqueda con el fin de facilitar el acceso al sitio del vendedor; c) la utilización de un nombre de dominio distinto de primer nivel diferente al del Estado miembro en que está establecido el vendedor; d) el uso de nombres de dominio neutros; e) la descripción de itinerarios desde otro u otros Estados miembros al lugar de la prestación del servicio; f) la mención de una clientela internacional formada por clientes domiciliados en diferentes Estados miembros, concretamente mediante la presentación de testimonios de dichos clientes.

\footnotetext{
${ }^{30}$ El artículo 6 Reglamento (CE) 593/2008 no protege a quien asume el riesgo de adquirir en el extranjero, bien porque a tal persona se le supone la consciencia de estar entrando en un contrato internacional en tales casos o la preparación o los medios para hacer frente a una eventual sumisión del contrato a la ley extranjera (Vid. M. GuZMÁn ZAPATER, "El reglamento CE núm. 593/2008, del Parlamento Europeo y del Consejo, sobre ley aplicable a las obligaciones contractuales: régimen general, contratos de consumo y contrato individual de trabajo": régimen general, contratos de consumo y contrato individual de trabajo", Aranzadi civil: revista quincenal, núm. 2, 2009, pp. 2271-2278).

${ }^{31}$ Cfr. J. Carrascosa GonzÁlez, Ley aplicable a los contratos internacionales: El Reglamento Roma I, Colex, Madrid, 2009 , p. 277. La idea que subyace a esta opción de política legislativa es aparentemente persuasiva. Esto puede provocar lagunas de regulación en el caso de los consumidores activos, que sólo pueden colmarse por vía de desarrollo hermenéutico (Vid. F.J. Garcimartín Alférez, “Obligaciones contractuales” en A. Borrás Rodríguez (coord.), La Cooperación en Materia Civil en la Unión Europea: Textos y Comentarios, Thomson Aranzadi, Navarra, 2009, pp. 624-625).

32 J.C. Fernández Rozas, / S.A. SÁnchez Lorenzo, Derecho Internacional Privado, $10^{a}$ ed., Civitas Thomson Reuters, Navarra, 2020, libro electrónico. En consideración de la doctrina privatista francesa, la ley española debe ser concebida en sentido amplio como un conjunto de normas que se aplican a los bienes y servicios ofrecidos al consumidor fruto de las relaciones entre profesionales y consumidores (Vid. S. ABID MNIF, "Le droit de la consommation et le droit des contrats: quelle destinée ? Réflexions sur l'évolution du droit positif tunisien", Revue internationale de droit comparé, núm. 1, 2020, p. 128).

33 Vid. STJUE de 7 de diciembre de 2010, asuntos C-585/08 / C-144/09, Peter Pammer / Hotel Alpenhof GesmbH (ECLI:EU:C:2010:740); STJUE de 6 de septiembre de 2012, asunto C-190/11, Mühlleitner (ECLI:EU:C:2012:542); STJUE de 17 de octubre de 2013, asunto C-218/12, Emrek (ECLI:EU:C:2013:666).
} 


\section{C) Diferenciación entre consumidor activo y consumidor pasivo}

27. La distinción entre consumidor activo y consumidor pasivo ${ }^{34}$ sirve para imputar el riesgo asociado a la internacionalidad del contrato a quien lo genera ${ }^{35}$.

A estos efectos se va entender que, si la publicidad de un operador extranjero llega regularmente al Estado del consumidor, tal hecho constituye objetivamente un medio de promoción de sus productos o servicios en ese mercado ${ }^{36}$. En tal caso, si el consumidor contrata desde su Estado, aunque sea él quien haya tomado la iniciativa de dirigirse al profesional del otro Estado, el riesgo de internacionalidad corre a cargo del profesional y se aplicará la ley del consumidor ${ }^{37}$.

28. Desde el punto de vista de los consumidores, el consumidor pasivo no tiene que preocuparse por la procedencia nacional o extranjera del producto o servicio ofrecido, pues en todo caso, le protegerá la ley del Estado de su residencia habitual ${ }^{38}$. Este puede desentenderse de los problemas de ley aplicable y simplemente debe comparar los productos o servicios ofrecidos por sus elementos esenciales y por su precio ${ }^{39}$.

29. La pervivencia en el Reglamento (CE) 593/2008 de este tratamiento del consumidor activo resulta censurable, y su inclusión en el régimen general de designación de ley no es la solución más adecuada, ya que ignora la condición de parte débil que posee el consumidor activo al otorgarle la consideración de profesional ${ }^{40}$.

${ }^{34}$ Vid. F. Rango, "The Law Applicable to Consumer Contracts under the Rome I Regulation”, F. Ferrari / S. Leible (EDS.), Rome I Regulation. The Law Applicable to Contractual Obligations in Europe, Sellier, Munich, 2009, pp. 144-149.

${ }^{35}$ El Reglamento (CE) 593/2008, presenta tres preceptos de interés para determinar el régimen jurídico de los contratos de consumo: el artículo 23, el artículo 6 y el artículo 3.4, que es una de las novedades del citado Reglamento. En relación a este último precepto, interesa destacar ante qué situaciones se aplica. Pues según ciertos autores, presenta problemas en relación a la figura del consumidor pasivo con residencia habitual dentro de territorio comunitario, puesto que no son coincidentes las soluciones ofrecidas por el artículo 6 y del artículo 3.4; es decir, la lex fori del artículo 3.4, no siempre es la de la residencia habitual del consumidor, del artículo 6.1 y 6.2. Si bien, se puede afirmar en este sentido, que en virtud de la regla lex specialis, procede afirmar que el artículo 3.4 comprende situaciones no cubiertas por el artículo 6.1. y 6.2: contratos de consumo (consumidores pasivos) excluidos por razón de la materia, o incluidos, si no se realizan en las circunstancias que desencadenan la consecuencia prevista por el precepto, si además los elementos pertinentes de la situación se vinculan sólo al espacio comunitario (Vid. M. ReQuejo Isidro, “Contratos de consumo y Roma I: ¿un poco más de lo mismo?”, Anuario español de derecho internacional privado, núm. 8, 2008, pp. 498-499).

${ }^{36}$ Las actividades publicitarias y comerciales realizadas a través de páginas de Internet poseen una orientación global; el hecho de que los lugares de Internet sean accesibles desde cualquier país hace emerger una presunción favorable a que dicha publicidad y ofertas, cuando se trata de lugares interactivos, son realizadas en el país de la residencia habitual del consumidor (Vid. F. EstebAn DE LA Rosa, "Régimen jurídico de la contratación electrónica internacional de consumo en el sistema español de Derecho internacional privado", Aranzadi civil: revista quincenal, núm. 1, 2009, pp. 2177-2178).

${ }^{37}$ El principio del Estado de destino convierte en indiferente el contratar en el Estado del consumidor con un proveedor nacional o extranjero, pero no hace indiferente el ser un consumidor activo o pasivo dentro del territorio comunitario (Vid. M. VIRGós Soriano / F.J. Garcimartín Alférez, "Estado de origen VS. Estado de destino: las diferentes lógicas del Derecho Internacional Privado", Pacis Artes. Obra homenaje al profesor Julio D. González Campos, Tomo II, Edifer, Madrid, 2005, pp. 1804-1805).

${ }^{38}$ El consumidor pasivo extracomunitario que contrata con una empresa comunitaria cabría garantizarle la aplicación de la ley de la residencia habitual en aquellos casos en que el Derecho internacional privado del Estado ofreciera una solución parecida a laso consumidores europeos (Vid. B. AÑoveros Terradas, "Consumidor residente en la Unión Europea vs. consumidor residente en un estado tercero: a propósito de la propuesta de Reglamento Roma I", Anuario español de derecho internacional privado, núm. 6, 2006, p. 401).

${ }^{39}$ Esto aumenta la confianza de los consumidores y refuerza la competencia dentro del mercado del Estado del consumidor. Además, la aplicación de su propio Derecho reduce los costes de información del consumidor. Este ahorro de costes es especialmente visible en los casos litigiosos, donde a los costes de información se suman los de alegación y prueba del Derecho extranjero (Vid. M. Virgós Soriano / F.J. Garcimartín Alférez, F.J., "Estado de origen vs. estado de destino: las diferentes lógicas del Derecho internacional privado", InDret, Revista para el Análisis del Derecho, núm. 251, noviembre 2004, pp. 13-14).

${ }^{40} C f r$. JuÁrez PÉrez, P.: "La ley rectora de los contratos internacionales de consumo: el sistema del Reglamento no $593 / 2008$ ("Roma I")", Estudios de Deusto: revista de la Universidad de Deusto, vol. 58, núm. 1, 2010, pp. 62-63. En cuanto al consumidor activo intracomunitario, un sector de la doctrina considera que debe quedar protegido por la ley del Estado miembro donde contrata (Vid. M. REQUEJO IsIDRo, "Régimen de las garantías en la venta transfronteriza de los bienes de consumo: armonización en el mercado interior y Derecho nacional”, Revista española de derecho internacional, vol. 57, núm. 1, 2005, p. 263). 


\section{D) Contratos concluidos vía on line}

30. La evolución tecnológica, indudablemente, ha conducido a la expansión de los servicios prestados por vía electrónica, favoreciendo así el fenómeno de la contratación electrónica. La admisibilidad de la contratación vía Internet deriva, con carácter general, de la autonomía de la voluntad concedida a los contratantes para formalizar y configurar sus negociaciones. Ahora bien, la aplicación de las reglas generales a la contratación electrónica no es suficiente para garantizar la seguridad jurídica en el ámbito contractual, por ello, es necesario exigir ciertos requisitos que proporcionen a las partes intervinientes la necesaria confianza en la materialización de sus relaciones ${ }^{41}$.

31. Ciertamente, para valorar si un sitio de Internet va dirigido a un determinado país cabe entender que deben tomarse en consideración todos los elementos que permitan apreciar si, básicamente por su configuración, contenido y las actividades de sus responsables, el sitio web trata de captar clientes o influir en un determinado mercado ${ }^{42}$.

32. En general, la comercialización de productos a través de una $w_{e} b^{43}$, especialmente dirigida hacia el mercado donde el consumidor tiene su domicilio, es susceptible de quedar amparada bajo la forma de contrato de consumo.

Con ello, lo que se pretende es reforzar la protección al consumidor, ya que en el caso de Internet se hace más difícil determinar el lugar en que se realizan los actos necesarios para la celebración del contrato $^{44}$. Cabe pensar en aquellos casos en los que el contrato ha sido celebrado directamente a través de la página web del empresario que ha resultado accesible en el país del consumidor y, se puede apreciar con mucha claridad la existencia de una vinculación entre el contrato celebrado y la actividad del empresario en el país del domicilio del consumidor. También, parece razonable poder considerar que el mencionado vínculo existe cuando la consulta de la página web ha sido el motivo que ha determinado al consumidor realizar las gestiones necesarias para celebrar el contrato ${ }^{45}$.

33. Si el consumidor no dispone en el momento de la conclusión del contrato de una conexión a Internet, ni conoce la página web del empresario cuya actividad se dirigía a su país, cabe, ciertamente, entender que esta situación no ha de traer por consecuencia la aplicación de las normas de protección, en cuanto el contrato queda claramente desvinculado de la actividad del empresario ${ }^{46}$. Pero hay que tener en

${ }^{41}$ D. Carrizo Aguado / A. Álvarez Rodríguez, «Determinación de la competencia judicial internacional en aquellos contratos con condiciones generales celebrados vía on line: Análisis de la validez formal del pacto de sumisión expresa materializado con un "clic" en página web», Unión Europea Aranzadi, núm. 7, 2015, pp. 73-88.

${ }^{42}$ Entre los elementos que pueden ser relevantes, cabe mencionar: el idioma en que esté redactado el sitio; la moneda en que estén expresados los precios; la presencia de direcciones locales de contacto; la existencia de avisos legales acerca de los mercados en los que se comercializan o están disponibles los productos o servicios; el volumen de transacciones con sitio web en medios locales de un país o dirigidos, entre otros, a ese país o la inclusión de enlaces a su sitio en directorios locales del domicilio del demandado (Vid. P.A. De Miguel Asensio, "Contratación comercial internacional”, en J.C. Fernández Rozas, / R. Arenas García, / P.A. De Miguel Asensio, Derecho de los negocios internacionales, Iustel, Madrid, 2013, pp. 320-321).

${ }^{43}$ El comercio electrónico es una de las formas de intercambio comercial que conviven en la sociedad globalizada; su conocimiento y perfeccionamiento son factores fundamentales que deben ser implantados en el ámbito mercantil internacional. La descripción, identificación, precio y forma de pago del producto, son elementos fundamentales para crear confianza y credibilidad en los consumidores bajo esta forma comercial (Vid. C. PARRA Rodríguez, "La regulación jurídica internacional del comercio electrónico", en J.L. Collantes González / B. DE LA Vega Justribó (coords.), Derecho internacional económico y de las inversiones internacionales, vol. 2, Palestra Editores, Pueblo Libre, Perú, 2009, pp. 36-37).

${ }^{44}$ La última crisis global ha puesto más si cabe en evidencia la vulnerabilidad de los consumidores ante los nuevos modelos de negocio (Vid. L. Carballo PiñeIro, "Tribulaciones de Derecho Internacional Privado del consumidor sobreendeudado y sus acreedores" en M. CARBAllo FidAlgo (coord.), Sobreendeudamiento de consumidores. Estrategias para garantizar una segunda oportunidad, Boch, Barcelona, 2019, p. 329).

${ }^{45}$ En aquellos casos en los que la página web del profesional o su intermediario tenga una orientación global que a pesar de no estar específicamente dirigida a un Estado miembro puede concluir de manera más o menos continua contratos con consumidores residentes en la Unión, ello permitiría, atendiendo a los indicios del TJUE, determinar esa intencionalidad de manera análoga a aquellos casos en los que el profesional tiene su establecimiento dentro de la UE. (Vid. P.A. DE Miguel Asensio, “Competencia judicial y protección de los derechos de la personalidad en Internet”, Diario La Ley, núm. 7787, 2012).

${ }^{46}$ El elemento temporal también puede de interés para verificar la existencia de la vinculación necesaria entre la actividad 
cuenta que, una interpretación demasiada amplia perjudicaría a la empresa, pero una demasiada estricta tendría como consecuencia debilitar los derechos del consumidor ${ }^{47}$.

34. Concretar si un sitio web va o no dirigido al país del domicilio del consumidor resulta una cuestión controvertida ${ }^{48}$. La tradicional distinción entre sitios activos y pasivos ${ }^{49}$, tiene escasa importancia al concretar si una web se dirige a un país ${ }^{50}$; lo determinante es que el sitio esté configurado de tal manera que quepa entender que trata de captar clientes en el mercado del domicilio del consumidor y no que esos clientes hayan contratado a través del propio sitio web, pues pueden haber utilizado un medio diferente para contratar ${ }^{51}$. Mediante el uso de esas tecnologías puede llegar a ser posible con un alto gra-

del empresario en el país del consumidor y el contrato celebrado. En efecto, el cumplimiento del requisito implica que la actividad del empresario no se ha dirigido, ni se ha realizado, en el país del consumidor como consecuencia de un contrato previo entre el empresario y el consumidor, pues en este caso no cabe apreciar la vinculación necesaria entre la actividad previa del empresario y el contrato celebrado. En este sentido, no se puede tener en cuenta la actividad dirigida al país del consumidor a través de páginas web cuando éstas han comenzado a aparecer con posterioridad a la celebración del contrato con el consumidor, ni tampoco la existencia de esas páginas con anterioridad, cuando el contrato se ha celebrado tras la cancelación de dichas páginas (Vid. F. EstebAn DE LA Rosa, "El papel del nexo de causalidad en el sistema europeo de competencia internacional de los contratos de consumo: ¿una condición para el olvido?”, La Ley Unión Europea, mes 11, 2014, versión on line).

${ }^{47}$ Las nuevas tecnologías y en concreto Internet ha supuesto que esta cuestión sea muy controvertida y las normas aplicables no contienen ninguna definición al respecto. La publicidad en Internet tienen un alcance global y es en principio accesible desde todos los Estados. De acuerdo con este dato, habrá que analizar en cada caso concreto si concurren indicios suficientes para entender que el vendedor dirige su actividad a otro Estado al Estado donde tiene domicilio el consumidor. Tarea más difícil es encontrar el punto de equilibrio entre los intereses en conflicto (Vid. A. Paniza Fullana, "La Sentencia del Tribunal de Justicia de la Unión Española (Gran Sala) de 7 de diciembre de 2010: algunos aspectos relativos a la protección del consumidor en la contratación de servicios turísticos en Internet", Aranzadi Civil: Revista Doctrinal, núm. 11, 2011, pp. 58-60).

${ }^{48}$ Hay autores que consideran que cobra relevancia la distinción entre páginas activas y páginas pasivas, es decir, entre aquellas que permiten al consumidor la adquisición directa del producto o servicio por medios electrónicos, interactuando a través de la web; y aquellas otras en las que el consumidor no puede adquirir directamente en Internet, utilizándose la página como mero escaparate de negocio. En el primer supuesto, nos encontramos ante un criterio casi determinante de la voluntad del prestador de dirigir su actividad al Estado miembro del domicilio del consumidor, que se fundamenta en la celebración del contrato y en la falta de empleo de medios técnicos que impidan la adquisición a consumidores domiciliados en dicho territorio. En cuanto a las páginas pasivas operaría la presunción contraria, es decir, no se podría interpretar que el prestador dirige su actividad al Estado del domicilio del consumidor, por el mero hecho de que la página sea accesible desde dicho Estado (Cfr. P. MÁrquez Lobillo, "Aplicación de las normas comunitarias sobre competencia judicial a los contratos de consumo electrónicos: interpretación del art. 15.1. c del Reglamento 44/2001”, en G.J. Jiménez SÁnchez / A. Díaz Moreno, (dirs.), J. Brenes CortéS / I. López de la Torre / M. Pacheco Cañete, (coords.), Estudios de Derecho del Comercio Internacional. Homenaje a Juan Manuel Gómez Porrúa, Marcial Pons, Madrid, 2013, p. 675). Valorar la voluntad del profesional para precisar el concepto de «actividad dirigida» no contenida ni en el Reglamento (UE) 1215/2012 ni en el Reglamento (CE) 593/2008, hace necesario acudir a la jurisprudencia y así entrelazar la relación entre ambos instrumentos comunitarios (Vid. E. LeIN, "The New Rome I / Rome II / Brussels I Synergy", Yearbook of Private International Law, vol. 10, 2008, pp. 177-198; F. PocaR, "Some Remarks on the Relationship between the Rome I and Brussels I Regulations", en F. Ferrari / S. LeIBLE (eds.), Rome I Regulation. The Law Applicable to Contractual Obligations in Europe, Sellier, Munich, 2009, pp. 343-348).

${ }^{49}$ Cuando ni del contenido de la página ni del comportamiento del empresario pudiera deducirse ningún tipo de intención de traficar en el mercado del consumidor, la página web debería ser considerada pasiva y, por tanto, los consumidores que realizaran algún tipo de operación con el empresario serían consumidores activos y no gozarían de la regulación tuitiva contenida en nuestro sistema de Derecho internacional privado: Vid. I. Heredia Cervantes, "Consumidor pasivo y comercio electrónico internacional a través de páginas Web”, Revista jurídica Universidad Autónoma de Madrid, núm. 5, 2001, pp. 86-87.

${ }^{50}$ No es de suma importancia que el sitio web sea interactivo o pasivo, pues según las circunstancias del caso un sitio web pasivo puede ser equivalente a dirigir actividades comerciales o profesionales a otros Estados miembros. Sin embargo, parte de la doctrina entiende que, si el sitio web es pasivo, no existiría Stream-of-Commerce, es decir, no se entendería que el empresario dirige su actividad mediante Internet al país del domicilio del consumidor. Aunque la publicidad comercial sea visible en un país, la imposibilidad de actuar de modo interactivo online para adquirir productos o servicios revelaría la voluntad del vendedor de no entrar en el mercado nacional de que se trate (Vid. E. CASTELLANOS RuIz, "Contrato internacional de consumo: voluntad de dirigir la actividad profesional al estado miembro del consumidor”, Revista Aranzadi de derecho patrimonial, núm. 34, 2014, pp. 166-167).

${ }^{51}$ Una de las vías a través de las cuales las empresas de comercio electrónico que pretenden operar en varios mercados organizan su estructura es mediante la creación de sitios diferentes para los diversos países, no sólo como mecanismo que ayuda al control de los riegos legales sino también como respuesta necesaria ante las diferentes preferencias lingüísticas, sociales y culturales existentes según los países, también en el seno de la UE (Vid. P.A. De Miguel Asensio, "Mercado global y protección de los consumidores", en L. Cotino HuEso (coord.), Consumidores y usuarios ante las nuevas tecnologías, Tirant lo Blanch, Valencia, 2008, pp. 163-167). 
do de fiabilidad para el titular de un sitio web conocer el país en el que se encuentra ubicado el ordenador desde el que un usuario trata de acceder a sus contenidos o contratar sus servicios o productos.

35. Sin lugar a dudas, Internet ha supuesto un reto para la defensa de los derechos de los consumidores que adquieren bienes y servicios a través de la red $^{52}$. Los consumidores electrónicos transfronterizos se sitúan en un escenario nuevo y desconocido con interrogantes sobre la subsistencia de normas, instrumentos y criterios tradicionales de la contratación clásica. El atractivo de acceder desde cualquier parte del mundo a lo más distantes mercados, a los productos y servicios más variados, se configura como un reclamo difícil de soslayar por los consumidores y usuarios ${ }^{53}$.

36. La aplicación de las reglas generales a la contratación electrónica no es suficiente para garantizar la seguridad jurídica en el ámbito contractual, por esa razón, es necesario exigir ciertos requisitos formales que proporcionen a las partes intervinientes la necesaria confianza en la materialización de sus relaciones. Los problemas encontrados por el consumidor -escasez de información, publicidad engañosa, información no precisa, etc.-, hacen que, efectuar una eventual reclamación no sea del todo sencilla ${ }^{54}$.

\section{Las cláusulas abusivas a debate en torno a la Directiva 93/13/CEE}

\section{Aclaración preliminar}

37. El amplio clausulado que suelen contener los contratos tipo, normalmente bajo la fórmula de contratos con cláusulas generales, hace que nazcan indiscutiblemente la desigualdad entre ambas partes ${ }^{55}$. También, existe un temor común que consiste en pensar que los comerciantes pueden abusar del poder que les da su pericia y experiencia en la materia a la que se dedican. En ese panorama de desconfianza y desigualdad, los consumidores tienen que tomar decisiones entendiéndolas en teoría por completo -o al menos en su mayor parte- para asimilar los intereses de quienes pretenden vender su producto, integrar sus propios intereses y entender sus eventuales sesgos ${ }^{56}$.

38. El escenario para la determinación de la naturaleza abusiva de las cláusulas no es sencillo, pues su apreciación en conjunto puede ser relevante para enjuiciar la naturaleza abusiva de las cláusulas

${ }^{52}$ Lógicamente, en la última década se ha logrado mejorar las normas de protección de los consumidores, pero no debe caer en baldío su adecuación ante los retos actuales de los mercados tildados por su constante evolución. Pues bien, en la esfera de la explosión digital, el legislador europeo debe mantenerse firme, con plena pertinencia y capacidad para abordar nuevos designios palpables en la economía 4.0.: D. CARrizo Aguado, "Posicionamiento de los consumidores en el mercado único digital desde una perspectiva internacional privatista" en L. García Álvarez y J. M. Martín Rodríguez (dirs.), El mercado único en la Unión Europea. Balance y perspectivas jurídico-políticas, Dykinson, Madrid, 2019, p. 31.

${ }^{53}$ Siempre y en todo caso, se ha de articular mecanismos para proteger a los consumidores y usuarios de los daños y perjuicios que puedan sufrir a consecuencia del alcance global de la red, infracciones que ser caracterizan esencialmente por su repercusión transfronteriza y supuestos de plurilocalización de daños o de ilícitos a distancia. Vid. A. HeRnÁNDEZ FERNÁNDEZ, "Los consumidores y usuarios en el entorno digital de internet: la responsabilidad civil extracontractual de los proveedores o «ISP»" en L. Cotino Hueso (coord.), Consumidores y usuarios ante las nuevas tecnologías, Tirant lo Blanch, Valencia, 2008, pp. 644-645.

${ }^{44}$ D. Carrizo Aguado, "Inmersión del consumidor transfronterizo en la contratación electrónica: una visión desde el derecho privado europeo", en A. Salinas de Frías y E.J. Martínez Pérez (dirs.), A. Sánchez Frías y F. Peña Díaz (coords.), La Unión Europea y la protección de los derechos fundamentales, Tirant lo Blanch, Valencia, 2018, p. 175.

${ }^{55}$ La protección adecuada al consumidor como parte del contrato considerada económicamente más débil y jurídicamente menos experta que su cocontratante profesional, lo ha reiterado el Tribunal de Luxemburgo en sendos pronunciamientos: STJCE de 20 de enero de 2005, C-464/01, Gruber, EU:C:2005:32; STJCE de 20 de enero de 2005, C-27/02, Engler, EU:C:2005:33 y STJCE de 14 de mayo de 2009, C-180/06, Ilsinger, EU:C:2009:303. Sobre esta última decisión: vid. M. REQUEJo IsIDRO, "La promesa de premio en la Jurisprudencia del TJCE (A propósito del asunto C-180/06, Ilsinger)", Noticias de la Unión Europea, núm. 316, 2011, pp. 125-135).

${ }^{56}$ T. Hualde MAnso, "El consumidor ignora el contenido de su contrato. La falta de lectura en los contratos de adhesión", Indret: Revista para el Análisis del Derecho, núm. 4, 2019, p. 16. 
contractuales accesorias ${ }^{57}$. Más aún, la vulneración del deber de transparencia contraria a las exigencias de la buena fe se convierte así en criterio directo de abusividad de la cláusula concernida, en la medida en que la previsibilidad del riesgo del que el consumidor no ha sido informado constituye la clave del juicio de su validez ${ }^{58}$. La conexión entre falta de transparencia y abusividad pasando por la noción de desequilibrio es plausible normativamente ${ }^{59}$.

\section{Reglas de juego entre la Directiva 93/13/CEE y el Reglamento (CE) 593/2008}

39. El ámbito de aplicación de la Directiva 93/13/CEE del Consejo, de 5 de abril de 1993, sobre las cláusulas abusivas en los contratos celebrados con consumidores ${ }^{60}$ incluye todos los contratos de consumo y no sólo los contemplados por el artículo 6 Reglamento (CE) 593/2008 ${ }^{61}$. Además, el marco de protección no quedará enmarcado únicamente con referencia a la ley de la residencia habitual del consumidor, sino que también se tendrá en cuenta la ley que presente «vínculos estrechos» ${ }^{62}$.

La «relación estrecha con el territorio de un Estado miembro» tiene por finalidad permitir que se tomen en consideración diversos elementos de conexión en función de las circunstancias del caso concreto $^{63}$.

${ }^{57} \mathrm{La}$ "tesis de las materias excluidas", conduce a una situación en la que la cláusula que describe el objeto principal del contrato puede ser apreciada en cuanto a su carácter abusivo, pero sólo bajo la condición de que no se haga referencia al objeto principal ni a la relación calidad/precio ( $c f r$. S. WhITTAKER, "Contratos abusivos, cláusulas abusivas y prácticas comerciales desleales", en S. Cámara Lapuente (dir.), E. Arroyo i Amayuelas, (coord.), La revisión de las normas europeas y nacionales de protección de los consumidores: más allá de la Directiva sobre derechos de los consumidores y del Instrumento Opcional sobre un derecho europeo de la compraventa de octubre de 2011, Civitas-Thomson Reuters, Navarra, 2012, p. 514).

${ }^{58}$ M. CARballo FidAlgo, "Hacia un concepto autónomo y uniforme de cláusula abusiva. La jurisprudencia del TJUE y su recepción por los tribunales españoles", Indret: Revista para el Análisis del Derecho, núm. 1, 2019, p. 42.

${ }^{59}$ A pesar de que la cuestión de la falta de transparencia material se analice en sede de desequilibrio/abusividad, no puede obviarse que la exigencia de transparencia protege la formación de la voluntad y persigue, por tanto, que el adherente no se vincule a cláusulas cuyo real significado no resulte comprensible o no haya comprendido por otros medios (Vid. C.I. AsuA GonZÁLEZ, "La falta de transparencia de las cláusulas no negociadas individualmente en la contratación con consumidores en el Derecho español”, Anuario de derecho privado, núm. 1, 2019, pp.69-70.

${ }^{60}$ DOCE núm. 95, de 21 de abril de 1993. El sistema de protección establecido en la Directiva se ciñe de una parte a los contratos celebrados entre profesionales y consumidores y de otra, a las cláusulas contractuales no negociadas individualmente. Para un estudio en la materia de la mano del Derecho comunitario, vid. M. CARBallo Fidalgo, La protección del consumidor frente a las cláusulas no negociadas individualmente. Disciplina legal y tratamiento jurisprudencial de las cláusulas abusivas, Bosch, Barcelona, 2013, pp. 21-60. En cuanto al control y transparencia de las cláusulas abusivas, vid. E. ARroyo AmAYUELAS, "No vinculan al consumidor las cláusulas abusivas: del Derecho civil al procesal y entre la prevención y el castigo" en E. ARROyo Amayuelas / A. Serrano Nicolás (dirs.), La europeización del Derecho Privado: cuestiones actuales, Marcial Pons, Madrid, 2016, pp. 65-96; L. Blanco PÉRez-Rubio, "El control específico sobre el contenido de los clausulados negociales predispuestos de carácter abusivo", Revista crítica de derecho inmobiliario, Año núm. 91, núm. 749, 2015, pp. 1099-1142; J. DomínGUEZ RoMERO, "La fiscalización de los elementos esenciales del contrato celebrado con consumidor: ¿fin de una controversia?", Revista Aranzadi de derecho patrimonial, núm. 27, 2011, pp. 155-176; M. GómEZ DE Liaño FonseCA Herrero, "El control de oficio de las cláusulas abusivas. El juez nacional como garante de la protección del consumidor", Revista de derecho de la Unión Europea, núm. 26, 2014, pp. 313-328; M. RodríguEz-PiñERo y Bravo-Ferrer, "Cláusulas contractuales abusivas y proceso monitorio", Diario La Ley, núm. 8723, 2016, versión on line.

${ }^{61}$ STJUE de 28 de julio de 2016, asunto C-191/15, Amazon, EU:C:2016:612. Las disposiciones legales que regulan las cláusulas abusivas y que desarrollan la Directiva 93/13/CEE constituyen normas imperativas cubiertas por el artículo 6.2 Reglamento (CE) 593/2008.

${ }^{62}$ En el propio artículo 6.2 Directiva 93/13/CEE del Consejo se plantea un problema de compatibilidad con el propio artículo 6 Reglamento (CE) 593/2008 (Vid in extenso, J.J. EzQuerRa Ubero, "El consumidor protegido por el derecho comunitario" en $\mathrm{M}^{\mathrm{a}}$. P. CAnedo Arrillaga (coord.), Derecho de consumo: actas del Congreso Internacional sobre Derecho de Consumo, Tirant lo Blanch, Valencia, 2009, pp. 725-727; J.C. Fernández Rozas / S. SÁnchez Lorenzo, Derecho Internacional Privado, $9^{a}$ ed., Civitas Thomson Reuters, Navarra, 2016, libro electrónico).

${ }^{63} \mathrm{Vid}$. A. QuiÑonES ESCÁMEZ, "Incorrecta transposición de la noción de "vínculo estrecho con el territorio comunitario" de las Directivas de consumo (STJCE de 9-9-2004, as. 70/03 Comisión c/ España)", Revista de Derecho Comunitario Europeo, Año núm. 9, núm. 21, 2005, pp. 540-542; id. "Concepto de «vínculo estrecho» en las Directivas de consumo: repercusiones de la STJCE (as.70/03 comisión C. España) en las leyes nacionales y en la propuesta de reglamento "Roma I" (2005)” en A-L. CALVO Caravaca / J. Carrascosa González (dirs.), Estudios sobre contratación internacional, Colex, Madrid, 2006, pp. 465-480. 
40. La vinculación del contrato con el país designado por el Reglamento (CE) 593/2008 debe ser una conexión puramente formal, nominal, fugaz, anecdótica, y aparente, pero no sustancial ni real; solo en ese caso, los vínculos del contrato con otro país pueden ser "manifiestamente más estrechos" que los que existen con el país al que conducen las conexiones más rígidas ${ }^{64}$.

41. Por lo tanto, la aplicación del artículo 6 Reglamento (CE) 593/2008 se hace depender de la voluntad de las partes, esto es, de que estas acudan al proceso con la prueba de la ley extranjera. De este modo, se compromete la obligatoriedad del propio Reglamento y su carácter de instrumento directamente aplicable y se pone en cuestión su finalidad principal, la de unificar la Ley aplicable en los Estados miembros de la UE a los contratos internacionales a distancia ${ }^{65}$.

\section{3. ¿Quién es un verdadero consumidor?}

42. En el ámbito del Derecho de la Unión Europea no existe un concepto unívoco de consumidor puesto que cada Directiva contiene una definición del mismo a los efectos de su aplicación ${ }^{66}$. En cualquier caso, será considerado consumidor final en el ámbito privado aquel que no participa en actividades comerciales o profesionales y, que sólo engloban los contratos celebrados para satisfacer las propias necesidades de consumo privado del individuo ${ }^{67}$

La finalidad no profesional, comercial o empresarial de la adquisición del bien o de la contratación de la prestación de un servicio será nuclear para su apreciación, por ende, la satisfacción de necesidades de carácter privado marcará la senda doméstica propia de las personas físicas, cuestión que, si bien, puede desconocerse en personas jurídicas de Derecho privado que realicen actividades extraprofesionales y que merezcan ser consideradas como consumidores o usuarios en determinadas relaciones jurídicas.

43. Para ello, deben concurrir los requisitos que ha de reunir todo «consumidor» para merecer esta calificación jurídica y, en cualquier caso, no podrán realizar actividades de producción o de comercialización de bienes o servicios para el mercado ${ }^{68}$.

Así, se puede afirmar que cuando una persona celebra un contrato para usos relacionados con su actividad profesional debe considerarse que se encuentra en igualdad de condiciones con su cocontratante ${ }^{69}$

${ }^{64}$ Cfr. J. Carrascosa González, "La cláusula de excepción y los contratos internacionales: La crisis del principio de proximidad" en C. Esplugues Mota / G. Palao Moreno (eds.), M. Penadés Fons (coord.), Nuevas fronteras del derecho de la Unión Europea: liber amicorum: José Luis Iglesias Buhigues, Tirant lo Blanch, Valencia, 2012, pp. 463-464.

${ }^{65} \mathrm{Vid}$. P. OReJudo DE Los Mozos, "Imperatividad de la norma de conflicto y prueba del derecho extranjero en los reglamentos sobre ley aplicable a las situaciones privadas internacionales" en X. ABel LluCh / J. Picó I JunOY / M. Richard GonZÁLeZ (DIRS.), La prueba judicial: Desafios en las jurisdicciones civil, penal, laboral y contencioso-administrativa, La Ley, Madrid, 2010, 477-498.

${ }^{66}$ A modo de ejemplo, la Directiva 2011/83/UE, de 25 de octubre, sobre derechos de los consumidores, determina como consumidor a la persona física que actúe con propósito ajeno a su actividad comercial, empresa, oficio o profesión (artículo 2.1.); la Directiva 2005/29/CE del Parlamento Europeo y del Consejo, de 11 de mayo de 2005, lo define como toda persona física con un propósito ajeno a su actividad económica, negocio, oficio o profesión (artículo 2.a.); la Directiva 2000/31/CE del Parlamento Europeo y del Consejo, de 8 de junio de 2000, lo conceptualiza como aquella persona física con un propósito ajeno a su actividad económica, negocio o profesión (artículo 2.e.). Ninguna Directiva de las mencionadas, entre otras, coincide en la literalidad del concepto. Lo que sí que tienen en común es que no incluyen a las personas jurídicas, suelen emplear el término subjetivo de "propósito", y el legislador comunitario tiende a la delimitación negativa (vid. J. CAYÓN DE LAS CUEVAS, "Configuración normativa y técnicas de tutela del consumidor en el Derecho de la Unión Europea" en J.L. Tomillo Urbina (dir.) / J. Álvarez Rubio (coord.), La protección jurídica de los consumidores en el espacio Euroamericano, Comares, Granada, 2014, pp. 55-57).

${ }^{67}$ S. CÁmaRa Lapuente, "El concepto legal de «consumidor» en el Derecho privado europeo y en el Derecho español: aspectos controvertidos o no resueltos", Cuadernos de derecho transnacional, vol. 3, núm. 1, 2011, pp. 86-87.

68 J.M., Busto LAGo, "La posición del consumidor y del usuario en el Ordenamiento jurídico español" en AA.VV., Reclamaciones de consumo. Materiales para la construcción de un Tratado de Derecho de consumo, $4^{\mathrm{a}}$ ed., Aranzadi, Navarra, 2020, libro electrónico.

${ }^{69}$ STJCE de 20 enero de 2005, asunto C-464/01, Gruber, EU:C:2005:32 (vid. B. Añoveros Terradas, "Delimitación de los supuestos internacionales en los que se justifica el forum actoris a favor del consumidor (A propósito de las sentencias del TJCE en 
44. Hemos de detenernos, brevemente, para indicar ciertos detalles acerca de la concepción de "consumidor medio" ofrecidos por la jurisprudencia emanada del Tribunal de Justicia de la Unión. Será el asunto Gut Springenheide ${ }^{70}$, primer pronunciamiento del Tribunal de Luxemburgo, donde encontramos la identificación conceptual en el que es definido como aquel que está normalmente informado y razonablemente atento y perspicaz (apartado 31$)^{71}$. Un sector doctrinal sostiene que, esta idea supone una regresión en la tutela ofrecida al consumidor por las diferentes normas europeas. Por ello, se debe interpretar de manera restrictiva quedando residenciado de manera exclusiva al ámbito de las prácticas comerciales desleales, bien sean engañosas o agresivas ${ }^{72}$.

45. En cuanto a la normativa interna española en materia de Derecho de consumo, debemos rese-

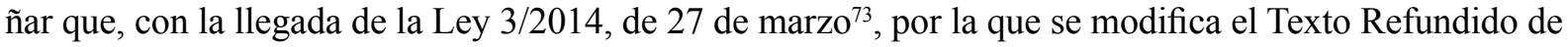
la Ley General para la Defensa de los Consumidores y Usuarios ${ }^{74}$, el legislador español ofrece una nueva redacción a los artículos 3 y 4 de dicha norma, relativa a los conceptos de consumidor y empresario. Sobre este cimiento, en consideración de la doctrina civilista, consumidor y empresario son dos caras de la misma moneda. Si contratas como consumidor, no eres empresario; y si contratas como empresario, no eres consumidor. Pero siempre que contratas, o lo haces como consumidor, o como empresario. No cabe una tercera posibilidad. ${ }^{75}$

$\mathrm{Su}$ artículo 3 distingue entre consumidor persona física y consumidor persona jurídica o una entidad sin personalidad jurídica. Ello no supone contravenir el espíritu del legislador europeo, en razón de que, aun cuando sea una Directiva de máximos o de armonización plena, al tratarse de sujetos no incluidos en el ámbito de aplicación de la misma, es decir, materia no armonizada, los Estados miembros disponen de libertad regulatoria al respecto.

Sobre este particular, la doctrina más consolidada estima que, la finalidad del artículo 3 in fine es clara: incluir en el concepto de consumidor a algunos entes sin personalidad jurídica, como las comunidades de propietarios, y excluir a las personas jurídicas y entes sin personalidad que se constituyen con un claro ánimo de lucro, como son las sociedades mercantiles, o las comunidades de bienes constituidas por varios sujetos para operar en el mercado ${ }^{76}$.

los asuntos Johann Gruber y Petra Engler)”, Diario La Ley, núm. 6264, 2005; J. VANnerom, Consumer Notion: Natural or Legal Persons and Mixed Contracts, Landmark cases of EU consumer law: in honour of Jules Stuyck, Intersentia, Cambridge, 2013, pp. 57-72).

${ }^{70}$ STJCE de 16 de julio de 1998, C-210/96 (EU:C:1998:369).

${ }^{71}$ L. GonZÁlez VAQuÉ, "La noción de consumidor normalmente informado en la jurisprudencia del Tribunal de Justicia de las Comunidades Europeas: La Sentencia Gut Springenheide”, Derecho de los negocios, núm. 103, 1999, pp. 1-15; A. Martínez Gutiérrez, "El carácter engañoso de la marca de empresa (comentario a la sentencia del Tribunal de Justicia de las Comunidades Europeas de 16 de Julio de 1998, asunto C-210/96)", Noticias de la Unión Europea, núm. 194, 2001, pp. 29-44; F. Palau Ramírez, "El consumidor medio y los sondeos de opinión en las prohibiciones de engaño en Derecho español y europeo. A raíz de la Sentencia del TJCE de 16 de julio de 1998, AS. C-210/96, Gut Springenheide", Actas de Derecho industrial y derecho de autor, Tomo XIX, 1998, pp. 367-395.

72 J. CAYÓN DE LAS Cuevas, "Configuración normativa y técnicas de tutela del consumidor en el Derecho de la Unión Europea”, en J.L. Tomillo Urbina, (dir.), J. Álvarez Rubio (coord.), La protección jurídica de los consumidores en el espacio Euroamericano, Comares, Granada, 2014, pp. 57-59.

${ }^{73}$ BOE núm. 287, de 30 de noviembre de 2007. La finalidad primera de la Ley 3/2014 es incorporar la Directiva 2011/83/ UE, de 25 de octubre, sobre los derechos de los consumidores (DOUE núm. 304, de 22 de noviembre de 2011). Interesa destacar, entre otros, los siguientes comentarios sobre la misma, vid: M.J. MARín LóPEz, "La Directiva 2011/83/UE: esquema general, ámbito de aplicación, nivel de armonización y papel de los estados miembros", Revista CESCO de Derecho de Consumo, núm. 1, 2012, pp. 8-21; I. Raluca Stroie, "La Directiva 2011/83/UE, sobre los derechos de los consumidores, desde sus orígenes hasta la publicación en el diario oficial de la Unión Europea", Revista CESCO de Derecho de Consumo, núm. 1, 2012, pp.1-7.

${ }^{74}$ BOE núm. 287, de 30de noviembre de 2007.

${ }^{75}$ Cfr. MARÍN LÓPEZ, M.J., "Concepto de consumidor y préstamo para financiar una futura actividad empresarial. Comentario a la STS de 11 de abril de 2019 (RJ 2019, 1364)", Cuadernos Civitas de jurisprudencia civil, núm. 112, 2020, pp. 269-288.

${ }^{76}$ M.J. MARín LóPez, "El "nuevo" concepto de consumidor y empresario tras la Ley 3/2014, de reforma del TRLGDCU", Revista CESCO de Derecho de Consumo, núm. 9, 2014, pp. 13-15; Estallo, M.L., "El eterno debate sobre la condición de consumidor", Actualidad Civil, núm. 5, 2020, versión on line. 


\section{Diagnóstico de las cláusulas no negociadas en la práctica comercial internacional}

46. Tomando en consideración lo apuntado por el Alto Tribunal Europeo en el asunto C-191/15, de 28 de julio de $2016^{77}$, con independencia del medio de celebración del contrato, una cláusula de elección de la Ley aplicable incluida por el empresario en las condiciones generales, la cual induce a posibles errores al consumidor dándole la impresión de que únicamente se aplica al contrato la Ley del Estado del domicilio del profesional, y, sin informar al consumidor de que está amparado por las disposiciones imperativas del país de su residencia habitual, tal y como reza el párrafo segundo, del artículo 6 Reglamento (CE) 593/2008, es abusiva, en el sentido del artículo 3.1 de la Directiva 93/13 ${ }^{78}$. Es más, cuando los efectos de una cláusula se determinen por disposiciones legislativas imperativas, es esencial que dicho consumidor sea informado por el profesional de dichas disposiciones ${ }^{79}$.

47. Ciertamente, el artículo 6, apartado 2 Reglamento (CE) 593/2008 reconoce la facultad de pactar el Derecho aplicable a un contrato de consumo, siempre que se garantice el respeto de la protección que le proporcionen al consumidor las disposiciones de la ley de su foro, que no podrán excluirse mediante acuerdo. De este modo, la legislación de la Unión autoriza en principio las cláusulas de elección de la ley aplicable.

48. Se infieren como transcendentales las consideraciones ofrecidas por el Abogado General en el asunto C-191/15 ${ }^{80}$ al entender que, una cláusula de elección de la ley aplicable redactada previamente que designa aplicable el Derecho del Estado miembro donde se encuentra el domicilio del profesional, sólo es abusiva si presenta ciertas características, propias de su tenor o contexto, que generan un desequilibrio importante entre los derechos y obligaciones de las partes.

Precisamente, el carácter abusivo de una cláusula puede resultar de una formulación que no cumple la exigencia de una redacción clara y comprensible enunciada en el artículo 5 de la Directiva 93/13/CEE. Dada la situación de inferioridad en que se halla el consumidor con respecto al profesional en lo que se refiere, en particular, al nivel de información, esa exigencia debe ser objeto de una interpretación extensiva ${ }^{81}$.

${ }^{77}$ Asunto Verein für Konsumenteninformation, EU:C:2016:612. Como bien estima la doctrina extranjera, el pacto de Ley hacia el ordenamiento jurídico del empresario es justo en la medida en que también se hace referencia a la aplicación de las normas sustantivas de la Ley del Estado de residencia del consumidor: J. Rutgers, "Court of Justice of the European Union 28 July 2016, Case C-191/15 Verein für Konsumenteninformation v. Amazon EU Sàrl ECLI:EU:C:2016:612", Netherlands international law review, vol. 64, núm. 1, 2017, p. 175. Si bien, se observa una gran ausencia de conocimiento de aquellos problemas derivados de la elección de la Ley aplicable en los contratos de consumo, vid. G. RüHL, "The unfairness of choice-oflaw clauses, or: The (unclear) relationship between Article 6 Rome I Regulation and the Unfair Terms in Consumer Contracts Directive: VKI v. Amazon", Common market law review, vol. 55, núm. 1, 2018, p. 223. El asunto de la apreciación de oficio es un pilar importante en la protección de los consumidores, derivado directamente del principio de no vinculación establecido en la Directiva (CE) 93/13 y del carácter de orden público de dicha protección. Pero esta apreciación de oficio, lejos de ser un tema sin controversia, plantea en la práctica numerosas cuestiones. Una de ellas, es el alcance de dicho deber del juez nacional de apreciar de oficio las cláusulas abusivas de un contrato. Es decir, hasta dónde tiene el juez que extender esa búsqueda y apreciación de oficio en un contrato. Referente a dicha problemática, vid. MARTín FusTer, J.M., "El factor de pertinencia en la apreciación de oficio de la nulidad de cláusulas abusivas", Actualidad Civil, núm. 6, 2020, versión on line. De hecho, la grandiosa labor realizada por el TJUE en el Derecho de consumo, hace que se controlen las infracciones procesales a la luz del principio de tutela judicial efectiva (Vid. CLAVEL, S., "Protection juridictionnelle effective et rêgles de droit international privé", Journal du droit international, núm. 3, 2019, p. 700).

${ }^{78}$ La determinación de la Ley aplicable, así como, las cuestiones de jurisdicción, en un contexto de contratación transfronteriza con consumidores, y, en el marco de una economía digital, se está convirtiendo en una tarea de gran complejidad. Ambas cuestiones ilustran que, la Ley más efectiva para el consumidor será aquella que le genere confianza con el fin de facilitar los objetivos del Mercado interno, junto con la creación de un entorno digital transnacional en el que los consumidores están adecuadamente protegidos ( Vid. en este sentido, S. LAw, "At the Crossroads of Consumer Protection, Data Protection and Private International Law: Some Remarks on Verein für Konsumenteninformation v. Amazon EU”, European law review, núm. 5, 2017, p. 764-766).

79 STJUE de 26 de abril de 2012, asunto C-472/10, Invitel, EU:C:2012:242.

${ }^{80}$ EU:C:2016:388.

${ }^{81}$ El Tribunal de Justicia ha tenido ocasión de precisar que la exigencia de transparencia de las cláusulas contractuales establecida por la Directiva 93/13/CEE no puede reducirse sólo al carácter comprensible de aquéllas en un plano formal y 
49. Por consiguiente, una cláusula contractual, inserta en las condiciones generales de venta de un profesional no negociada individualmente, en virtud de la cual se impone de manera imperativa la aplicación de la Ley del Estado miembro del domicilio social del profesional y sea esta la que rija el contrato electrónico, aseveramos que es abusiva.

El motivo en el que se sustenta dicha nulidad resulta de la inducción a error al que es sometido el consumidor $^{82}$; la escasez de información ${ }^{83}$ hace que este descarte el amparo legal que, sin lugar a dudas, dispone en virtud del artículo 6, apartado 2, Reglamento (CE) 593/2008, garantizándole así, protección en virtud de la puesta en funcionamiento de las disposiciones imperativas del Derecho que sería aplicable, extremo que debe comprobar el órgano jurisdiccional nacional a la luz de todas las circunstancias pertinentes.

gramatical. Por el contrario, toda vez que el sistema de protección establecido por la Directiva 93/13/CEE se basa en la idea de que el consumidor se halla en situación de inferioridad con respecto al profesional en lo referido, en particular, al nivel de información, esa exigencia de transparencia debe entenderse de manera extensiva: Vid. STJUE de 30 de abril de 2014, asunto C-26/13, Kásler y Káslerné Rábai (EU:C:2014:282); STJUE de 26 de febrero de 2015, asunto C-143/13, Matei, y Matei (EU:C:2015:127) y STJUE de 23 de abril de 2015, asunto C-96/14, Van Hove (EU:C:2015:262).

${ }^{82}$ No debemos olvidar que el consumidor electrónico presenta características particulares que le convierten en una parte especialmente necesitada de tutela legal. Uno de los riesgos asumidos por el consumidor es el hecho de adentrarse en un ordenamiento jurídico extranjero que no conoce. Los problemas encontrados por este hacen que una eventual reclamación presente no pocas complejidades. Consecuentemente, será necesario protegerlo a través de normas específicas para evitar así evitar que descarte las diversas posibilidades legales de las que dispone frente al empresario ( $C f r$. D. CARrizo AguAdo, Régimen jurídico de las operaciones internacionales de consumo en los servicios turísticos digitales, Dykinson, Madrid, 2018, p. 155).

${ }^{83} \mathrm{La}$ información ofrecida por los empresarios ha de constituir una técnica adecuada para que los consumidores lean, entiendan y se comporten racionalmente (Vid. I. DE LA MAZA GAZMURI, "El mal que no quiero: la información como técnica de protección de los consumidores", Revista jurídica Universidad Autónoma de Madrid, núm. 31, 2015, p. 350 y p. 354). Toda transacción comercial deberá estar presidida por el principio de veracidad de la información (Vid. V. VeGA Clemente, "Consideraciones sobre la protección de los consumidores en el comercio electrónico", Revista de estudios económicos y empresariales, núm. 24, 2012, pp. 162-166). 